\title{
ARTICLE \\ Wild Edible Plants Used by the Tribes of Panvel and Uran Tahsils in Alibaugh District, India: Ethnobotanical Application and Tribal Recipes
}

\author{
V.M. Jamdhade ${ }^{*}$ \\ Department of Botany, V.P.M.'S B.N. Bandodkar College of Science, Thane, India
}

\section{ARTICLE INFO}

Article history

Received: 27 December 2021

Accepted: 13 January 2022

Published Online: 19 January 2022

Keywords:

Wild vegetable

Ethnobotany

Traditional knowledge

Tribals

Recipe

\begin{abstract}
The "Indus-Vedic" cultural heritage of India is well-known. Wild edible plants, sometimes known as weeds, are widely consumed in India's varied areas. Wild edible plants and weeds are essential for tribes' survival, both as a source of food and as a source of money, such as timber. This study aims to identify wild vegetables collected for ethnomedical purposes and their recipes by the local people, as well as determine the local uses and names of these plants, with the goal of closing the gap in traditional knowledge regarding the utility of wild plant species and tapping the hidden potential resources for proper utilization, exploitation, and nutritive evaluation. A field research study was conducted two years 2020-2021. 34 wild vegetable plant specimens were collected during this time. The names of the plants found in the area, as well as the parts that were used and how they were prepared, were examined and recorded. This type of extensive survey technique could assist aspiring scientists in learning about the health advantages of wild food plants and weeds, which can subsequently be combined to generate successful crop plants. Such a system will benefit in the mitigation of food shortages, the regeneration of infertile lands, and the enhancement of rural economies.
\end{abstract}

\section{Introduction}

Tribes' dependence on unconventional wild vegetables is because of their habitat in hilly areas surrounded by forest. The majority of their agricultural fields are on hills and are therefore less productive. The scarcity of cereals and pulses begins with the arrival of winter. Tribes go to the nearby forest on a regular basis to obtain forest produce to augment their nutrition. To fulfil their hunger, the tribals are constantly on the lookout for unusual wild foods that have been growing for years ${ }^{[1]}$.

For the uncommon wild vegetables, the monsoon is the most abundant season. These vegetables are abundant from July to September in forests, along hill slopes, nearby river banks, around ponds, and in and around their hamlets where abundance of cow dung is available for their good growth. The majority of wild vegetables are accessible for good growth throughout the first two

\footnotetext{
*Corresponding Author:

V.M. Jamdhade,

Department of Botany, V.P.M.'S B.N. Bandodkar College of Science, Thane, India;

Email:vmjamdhade@vpmthane.org
} 
months of the monsoon. Though the majority of wild vegetables are available to tribals during the first two months of the monsoon, just a few are left behind for their family members due to strong demand in the local taluka market. Because of their ethnomedicinal value, the unusual wild vegetable brings in extra money for the tribals.

Though functional food is higher in minerals, proteins, and beta-carotene than unusual green leafy vegetables, tribals' intake of functional food is lower due to nonavailability in bulk, improper cooking methods, and an excess of crude fibre; thus, tribals exhibit signs and symptoms of malnutrition, with growing children and lactating mothers being the main victims ${ }^{[2]}$. Fruits contribute more to tribal diets than cereals, however not to the extent recommended by the ICMR, which could be one of the causes of vitamin A deficiency among them.

The diets of diverse Indian tribal tribes were found to be seasonal, lacking in green vegetables, and high in crude fibre, according to studies ${ }^{[3]}$. Children, breastfeeding moms, and pregnant women are the most susceptible to such imbalanced nutrition. During the monsoon season, infectious disorders linked to malnutrition are especially common among tribals. In this season, tribal people's diets contain only a small amount of leafy vegetables, despite the fact that green leafy vegetables are readily available ${ }^{[4]}$. Fibre is abundant in a variety of wild vegetables. The primary impediment to the biological availability of proteins and vitamins is fibre. The oil is not included in the diet of the tribes. Milk and milk products are completely absent from their everyday dietary intake.

Several research on wild edible plants used by various groups in India have been undertaken, including edible plants from Maharashtra's Melghat forest ${ }^{[5]}$, plant resources from Maharashtra's Thane area ${ }^{[6]}$, and wild edible plants from India's Arunachal Pradesh ${ }^{[7]}$, wild edible plants from Annamalai ${ }^{[8]}$, Coimbatore district, Western Ghat ${ }^{[9]}$, Sikkim Himalayan plant dietary applications ${ }^{[10,11]}$. Tripura, India and Ahmednagar, Maharashtra ${ }^{[12]}$, biodiversity in Konkan Wild Vegetables ${ }^{[13,14]}$. Rural people eat wild edible plants as vegetables. Several investigations on traditionally used herbal remedies have been undertaken in Maharashtra (especially on the Western Ghat). In the Panvel and Uran regions, no effort had been done to document the diversity and utility of wild vegetables. As a result, the current research was designed to describe the variety of wild vegetables consumed by rural and urban residents in the Panvel and Uran areas of Albaugh, Maharashtra, India.

\section{Materials and Methods}

\section{Selection of the site}

Panvel and Uran are the most economically underdeveloped places since their human habitats are inaccessible to modern culture and civilization. The tribals in this area are still surrounded in a past era, without access to all of the modern amenities. Their anthropological dictionary is totally lacking of the magical word "science". For our research, we chose a rural location in Panvel and Uran taluka.

\section{Collection of Wild Vegetables}

Vegetable samples were collected on a quarterly basis in the study locations. In the Panvel and Nerul Navi Mumbai areas, vegetable samples were also collected from village elders, farmers, vegetable merchants, customers, and vegetable middlemen.

\section{Plant Identification}

Specimens were identified using standard procedures ${ }^{[15,16]}$ and Flora of Gujrat) with supporting information for ethnomedical uses and recipes ${ }^{[17-19]}$. Tribes were interviewed to learn about local vegetable names, habits, habitats, cooking methods, ingredients, current availability, distance travelled to acquire the vegetables, time gap before cooking, and quantity used in preparation.

\section{Results and Discussion}

Tribes consume largely leafy vegetables that grow like weeds in the wild ${ }^{[20]}$. According to the findings of this research, the Panvel and Uran areas are rich in wild vegetable species with enormous potential for human use, contributing favourably to the local economy and livelihoods of the many populations. In this work, a total of 34 wild edible plant species from 22 families and 29 genera have been found, classified, and discussed. Plant species' botanical names, as well as local names, habits, families, parts used, modes of usage, ethnomedicinal applications, and tribal recipes, are arranged alphabetically. With five species, the Cucurbitaceae family takes the lead, followed by Araceae with four species, the Yam family or Dioscoreaceae with three species, Vitaceae, Fabaceae, and Chenopodiaceae with two species respectively, and the rest with one species each.

The leaves, which represent 18 species, were found to be the most consumed part of the plant, followed by fruit (15 species), bulb/rhizome/corm/tuber (08 species), tender shoots (06 species), flowers/inflorescence (06 species), and seeds (02 species). Wild edible plants found in the 
research area were frequently used as vegetables in curry, soups, and pickles. Many of them are utilized for healing purposes due to their ability to cure a variety of diseases. Some are eaten raw, while others are cooked, and many are used as food substitutes when food is scarce.

According to the findings of this study, 98 percent of all plants documented have medicinal properties and are commonly used for common ailments such as coughs, asthma, stomach issues, skin infections, urine, and so on. According to the market survey, a total of 34 wild edible plants have commercial value among locals and are frequently sold in small markets or even transported to larger marketplaces nearby. The market price of these plants has been compared between the remote Uran market and Navi Mumbai town, and it has been discovered that the selling price of these plants doubles to triples once they reach urban areas. Some of these wild edible plants are isolated to rural populations and are not very popular in urban markets, according to reports.

1) Alylosia lineta Wight and Arn's. (Local Name: Jangli Tur Sheng, Family-Fabaceae).

Edible parts: Fresh leaves, young pods, and seeds are all edible portions.

Tribal recipe: young leaves are utilised as vegetables in this traditional dish. Salt is added to mature pods before they are boiled. The seeds are removed and consumed. Young pods are eaten directly.

Ethnomedicinal applications: Its ethnomedical uses include itching relief and the treatment of blood impurities. The malnourished child is given plain boiled seeds.

2) Amaranthus gangeticus (Local Name-Ran Math, Family-Amaranthaceae).

Edible parts: young leaves and tender shoots are edible parts.

Tribal recipe: Fresh young leaves and stem portions are boiled and served in curries or as a vegetable with a pinch of salt and chilies in a tribal dish.

Ethnomedicinal applications: Applications include wound healing, cough relief, and reducing the effects of alcohol.

3) Amorphophallus commutatus (Local Name: Shevli, Family: Araceae).

Edible Parts: All parts of the plant are edible, including tender shoots, leaves, flowers, and fruits.

Tribal recipe- Open inflorescence is fried on a light flame and served as a vegetable in a tribal dish. The leaves are cooked in water before being eaten.

Ethnomedicinal applications: Infusion is used to treat stomach issues in traditional medicine.

4) Amorphophallus sylvaticus, Roxb. Kunth. (Local name: Jangli Suran, Family- Araceae).

Edible parts- Corm, tender petiole, and young leaf are all edible components.

Tribal recipe- The corm is edible after being washed and boiled for a long time. Cut fresh young petioles into pieces, boil them, and eat them. Chopped young leaves are used as a vegetable.

Ethnomedicinal applications: Piles, coughing, and asthma are all treated with this herb.

5) Atriplex hortensis var. hortensis, (Local name: Chandan Batwa or Ran Batwa. Family Chenopodiaceae).

Edible part-The leaves are edible.

Tribal recipe-Cooked and consumed like a vegetable, the fresh leaves are used. Ingredients include salt and chilies.

Ethnomedicinal applications: A decoction of the leaves is used as a tonic, providing energy to weak patients. Lactating women should consume the vegetable to increase the amount of breast milk they produce.

6) Bambusa arundinacea Linn. (Local Name: Bamboo Comb), Family: Gramineae (Poaceae)

Edible parts-Part-tender shoots that are edible

Tribal recipe-The combs are peeled and sliced into little pieces, then heated in boiling water for a while before being thrown in with water. Bamboo is boiled and eaten with salt, chili and peppers.

Ethnomedicinal applications: Bambusa leaves, shoot and seeds used as astringent and laxative.

7) Brassica nigra Linn. (Local Name: Rai, FamilyCruciferae/Brassiceae).

Edible part- The leaves are edible.

Tribal recipe- Fresh leaves are cooked with onions and eaten as part of a tribal dish. Salt and chillies are the major ingredients.

Ethnomedicinal applications: Intestinal worms, skin infections, indigestion, stomach pain, and swellings are all treated with this herb.

8) Capparis moonii Wight. (Local Name-Pendra), Family-Capparaceae)

Edible part-Fruit

Tribal recipe- The fruits are sliced and the seeds are removed in this tribal dish. With some oil, chilies, and salt, the sliced pieces are fried on a low burner.

Ethnomedicinal applications: Seed paste is used as an antibacterial on wounds in traditional medicine. Also known as Anasarca.

9) Chenopodium album (Local Name: Chakwat, Family-Chenopodiaceae).

Edible part: Leaves

Tribal recipe- Fresh leaves are cooked with salt and chiles as a vegetable. 
Ethnomedicinal applications: Used to treat throat infections. After the symptoms of chickenpox appear, that plant's juice is mixed with honey and used to make the person suffer vomiting.

10) Colocasia antiquorum L. (Local Name-Arve, Family-Araceae).

Edible parts: Tubers

Tribal recipe- The tubers are pilled and cut into pieces, then washed in water and cooked as a vegetable; they can also be eaten raw after washing and roasting in hot ash, or cooked with oil, salt, and chilies and then consumed.

Ethnomedicinal applications: It has digestive qualities.

11) Colocasia esculenta (Local Name: Alu, Ghuiyan, Family: Araceae).

Edible parts: Leaves with a long succulent petiole and rhizome are edible.

Tribal recipe-Rhizomes are washed often, then cooked and eaten with salt and chiles after the skin has been removed.

Ethnomedicinal applications: Astringent, stimulant, and rubefacient effects are found in the leaf juice. Corm juice is a laxative that can also be used to reduce bleeding in piles. It is used to help breastfeeding women produce more milk.

12) Cucurbita maxima (Local Name: Danger, FamilyCucurbitaceae).

Edible parts-Tender shoots, leaves, flowers, and fruits are all edible components of the plant.

Tribal recipe-Open flowers are fried on a low flame and used as vegetables in a tribal dish. Cut the leaves into pieces, boil them in water, and eat them.

Ethnomedicinal applications: Flowers are used as an ethnomedicinal treatment for skin infections.

13) Dioscoria pentaphylla (Local Name: Gabholi, Family-Dioscoreaceae).

Edible parts-Flowers in inflorescence form are edible.

Tribal recipe- When male flowers are green, they are consumed, while female flowers are cream-colored. Male and female plant flower buds are used in curries as vegetables. Flower buds that have been cooked are delicious popular food delicious.

Ethnomedicinal applications: Aphrodisiac, it is said that eating a lot of flowers and vegetables can make you more attractive to other people.

14) Dioscorea bulbifera (Local name-Kadukand, family-Dioscoreaceae).

Edible part- The underground tubers are known as "kadukand" and are edible.

Tribal recipe- Underground kadukand can be made edible by treating it as follows: It is cleansed initially by removing the root hairs. They are properly washed in running water, peeled, and sliced into slices before being served with salt. They can be placed in hot ash for 2 to 3 hours before being cut into pieces and fried. Bulbul's vegetables are prepared in a manner that is comparable to that of potato tubers. The outside warty layer is removed first, and the inside section is used to prepare vegetables. It can also be roasted and eaten with salt in hot ash.

Ethnomedicinal applications: Ulcers, piles, diarrhea, and syphilis are all treated with dried and powdered tubers. The sedative qualities of young bulbils are wellknown.

15) Dioscorea oppositifolia L. (Local Name DukkarPaspoli, Family-Dioscoreaceae).

Edible parts-Underground tubers, flowers, and aerial bulbils are all edible.

Tribal recipe-Tubers are edible after several items of washing and boiling, and long-duration leaves are consumed when food is scarce. Bulbils are boiled after turning brown-black, the outer wart removed, and the interior starch consumed. Bulbils are also roasted and consumed after the outer coating has been removed.

Ethnomedicinal applications: The use of flowers is common. It promotes sexual desire in the diet. It's used to cure piles and stomach pain, among other things.

16) Garuga pinnata Roxb. (Local Name- Kakad, Family-Burseraceae).

Edible part: Fruits

Tribal recipe: the drupes can be eaten fresh, boiled, or pickled. They are highly acidic and have a cooling effect on the digestive system. To neutralize the raphides, fruits were combined with shevli during vegetable preparation.

Ethnomedicinal applications: The juice of the stem is used as a treatment for conjunctivitis opacity. Asthma can be helped by mixing leaf juice with honey.

17) Guizotia abyssynica Cass. (Local Name-Karale, Family-Compositae).

Edible part-Leaves

Tribal recipe- The leaves are finely chopped and fried on a low temperature, with salt and chillies added.

Ethnomedicinal applications: The oil is derived from seeds and has ethnomedicinal applications. It has a laxative effect. It can also be used on a person who is suffering from joint discomfort or Rheumatism. Ginger and castor oil are tainted with it.

18) Hibiscus cannabis Linn. (Local name: Ambadi.) Family Malvaceae

Edible part-Leaves

Tribal recipe-Fresh leaves are cooked with salt and chilies and consumed as a vegetable in this tribal dish.

Ethnomedicinal applications: cooked leaves with rice are given to people who have dyspepsia caused by 
Mahuwa oil. It's a pain reliever. If there is a problem passing urine, a decoction of seeds is given.

19) Holarrhena antidysentrica Wall. (Local NameKuda Sheng), Family-Apocynaceae).

Edible part: Pods

Tribal recipe-The pods are fine chopped in this tribal dish. These pieces are rinsed and cooked in a mild amount of oil with salt and chiles. It was prepared over low heat.

Ethnomedicinal applications-Alkaloids with therapeutic characteristics are abundant in plant parts, especially fruits. Roots and bark are used to cure diarrhea since they are anti dysenteric drugs. It's acidic, and it's good for digestion and cooling.

20) Leea indica Burm (Local Name-Bhane, Family-Vitaceae).

Edible part-young leaves and stem

Tribal recipe-There are two different types of tribal recipes.

- Pilled and chopped into small pieces, the young stem is boiled in water and eaten with salt. - The water is discarded, and the young stem is pilled and chopped, along with the leaves, and cooked on a low flame, sometimes with crabs.

Ethnomedicinal applications: The stem juice is used as an anthelmintic, and the tuber is used as an antiseptic for wound care.

21) Leea macrophylla Roxb. (Local Name- Dinda, Family-Vitaceae).

Edible part-The tender leaves and fruits

Tribal recipe-Fresh leaves and fruits are cooked with salt and chiles as a vegetable.

Ethnomedicinal applications: The root tubers are astringent and also have ethnomedicinal applications. Because of its healing properties, mucilage is applied to wounds and sores.

22) Luffa tuberosa Roxb. (Local Name-Satpute, Family-Cucurbitaceae).

\section{Edible part-Fruits}

Tribal recipe-The fruits are cut open and the seeds are removed in this tribal dish. Then it was sliced, salted, and set aside for a while. Then they were rinsed and cooked on low heat.

Ethnomedicinal applications: a decoction of the roots is used as a stomachic medicine. The seeds are crushed into a paste and applied to swollen areas of the body.

23) Madhuca longifolia Linn. (Local Name-Mahuwa, Mowa, Tode, Family -Sapotaceae).

Edible parts: Flowers, seeds and fruits

Tribal recipe-Flowers and fruits are lightly cooked and eaten with salt in a tribal recipe. Seeds that have been extracted for oil can also be eaten.
Ethnomedicinal applications: Madhuca leaves are effective in the treatment of Eczema. Tree flowers help to breastfeed women produce more milk. Snake poisoning is treated with seeds. Seeds are used to extract oil, which is then consumed. Flowers are combined with putrefied jaggery to make Mahuwa liquor, a fermented wine.

24) Manihot esculana Pohl (Local Name: Tapioca, Family- Euphorbiaceae).

Edible part: Tuberose roots

Tribal recipe-Tapioca roots are consumed after boiling and roasting in a tribal recipe. Root flour meal is consumed after it has been boiled or roasted.

Ethnomedicinal applications: If you have a constipation problem, use it as an appetizer. Wounds and ulcers are also treated with this treatment. In dyspepsia and anorexia, it is used as an aperient.

25) Melothria heterophylaa Cogniaux (Local NameGomati, Family-Cucurbitaceae).

\section{Edible part-Fruit}

Tribal recipe-The fruits are chopped into little pieces, sprinkled with salt, and left for a few minutes in this tribal recipe. Then they're rinsed and fried in a small amount of oil on a low flame.

Ethnomedicinal applications: Its juice is used to treat stomach pain in folk medicine. Carminative

Social Application-A person whose parents have passed away is not permitted to eat the vegetable.

26) Momordica dioca Roxb. (Local Name-Kartoli, Family-Cucurbitaceae).

Edible parts- The immature fruits, as well as young leaves and tubers, are edible.

Tribal recipe-In urban areas, young fruits are in high demand. Curries with young green fruits are tribal recipe.

Ethnomedicinal applications: Tuberose roots are used in traditional medicine to treat bleeding piles, digestive and urinary problems.

27) Moringa oleifera Linn. (Local Name: Shevaga, Family-Moringaceae).

Edible parts-Fresh leaves, tender pods, and even flowers are edible.

Tribal recipe-young leaves and flowers are steamed before being mixed with gram flour, salt, and chilies in a tribal recipe. Only salt and chilies are used in the tribal habitat's inner.

Ethnomedicinal applications: This vegetable is used to treat eye issues, indigestion, and snake poisoning.

28) Nymphaea lotus Linn. (Local name-Bhishi, Kamal, Family-Nymphaeaceae).

Edible part: Underground tubers

Tribal recipe-Washing 4-5 times and then cooking with salt is a tribal dish. 
Ethnomedicinal applications: Rhizome is utilised in the treatment of diarrhoea, dysentery, general debility, and heart problems. In indigestion, vomiting, and dysentery, root stock churna is employed. A decoction of tubers is provided in the case of excessive heat in the body, as well as during the passage of seminal fluid through the urine.

29) Paracalyx scariosus Roxb. (Local Name-Ran Ghevda, Family-Fabaceae).

Edible part-young leaves and pods

Tribal recipe- Fresh young leaves are cooked with onion, salt, and chilies in a tribal recipe. Beans are removed from the pods and consumed after they have been boiled with salt.

Ethnomedicinal applications: Ethnomedicinal uses include scorpion bites and leg cramps.

30) Portulaca oleracea Linn. (Local name-Ghol, Family-Portulaceae).

Edible part- Stem and leaves

Tribal recipe-Fresh stems and leaves are lightly cooked and eaten with onions and chilies in the tribal recipe.

Ethnomedicinal applications: Seeds are a cooling diuretic that can be used to treat jaundice and diarrhea. They can also be used to treat burns and scalds. Skin problems, abscesses, wounds, coughs, and swellings are all treated with this herb. Also used for tiredness, difficulties breathing, and vision problems.

31) Praecitrullus fistulous Stocks (Local NameDhemse, Family-Cucurbitaceae).

Edible part-Fruit

Tribal recipe-Fresh fruits are eaten like a vegetable with salt and chilies in tribal recipes, and they are also utilized in curries.

Ethnomedicinal applications: Ethnomedicinal uses include the treatment of fevers, blood infections, and asthma.

32) Smithia purpurea (Local Name-Kaula), FamilyPapilionaceae

Edible part-Leaves

Tribal recipe-Chopped leaves are cooked for a few minutes on a low flame in this tribal recipe. A sufficient amount of oil, salt, and chili is used. When combined with crab legs, it is supposed to form a delicious dish.

Ethnomedicinal applications: Anthelmintic properties are found in the juice of the leaves. Malnourished babies are fed a paste made from young leaves to help them gain strength.

33) Solanum verbascifolium Linn. (Local Name Jungli Wangi, Family-Solanaceae).

Edible part-young fruits

Tribal recipe-Fruits are usually cooked for a few minutes in tribal dishes. Boiled water is discarded, and curries are made with vegetables.

Ethnomedicinal applications - In tribal medicine, leaves and fruits are used. Fruits have a laxative effect. Toothaches are treated with seeds.

34) Spondius pinnata (Linn.) Kurz. (Local NameAmbada, Family-Anacardiaceae)

\section{Edible part-Fruit}

Tribal recipe: The fruits are sliced and the seeds removed, then cut into pieces and cooked as a dry vegetable with salt and chilies in a small amount of oil. Fruits are also cooked in curries.

Ethnomedicinal applications: The seeds are powdered and applied to rashes, eruptive acne.

Many people in rural areas around the world depend on wild edible plants for food., made several attempts to compile a list of the wild foods found in Maharashtra's Vidarbha region ${ }^{[21-24]}$. Vegetables are high in vitamin A, and the vitamin B complex, as well as dietary fibre and phytochemicals. The nutrients found in wild vegetables also safeguard our bodies from starvation and nutrient deficiencies. That's why they're referred to as "protecting foods" ${ }^{25]}$. These unusual wild edible plants are rich in micronutrients and trace elements, as well as proteins and lipids ${ }^{[26,27]}$. According to a review of the research, eating enough vegetables can prevent you from chronic diseases like cancer, obesity, diabetes, cardiovascular disease, and metabolic syndrome.

\section{Conclusions}

People will have to depend on wild edible plant resources as an alternative to conventional ones in the near future to meet the increasing demands for food and nutritional requirements due to the increasing population pressure. As a result, plant resources play an important role in resolving a variety of issues such as shelter, food, and medicine. As a result, many of these wild plants have a high cultural value among the locals and are thus linked to their indigenous traditions.

\section{Acknowledgements}

The author expresses his gratitude to the villagers, local vegetable shopkeepers, and informants for their kind assistance and useful information, as well as all those who helped directly or indirectly in the fieldwork, and V.P. M.'S. B. N. Bandodkar College of Science, Thane (Autonomous) for moral support.

\section{References}

[1] Save, K.J., 1945. The Warlis Padma Publication Ltd. 
Bombay.

[2] Gupta, B.M., Bhandare, R., 1972. Nutritional status of tribal and nontribal rural per school children around Udaipur. Indian Journal Pediatrics. 39, 317326.

[3] Rao Nageshwara, C., Rao Narsinga, B.S., 1970. Absorption of dietary carotenes in human subject. American Journal Clinical Nutrition. 23, 105.

[4] Pant, K., 1996. Nutritive values of some non-conventional vegetables used in tribal area of Thane district M.Sc. Thesis Bombay University.

[5] Bhogaonkar Prabha, Y., Vishal, R., Marathe, Kshirsagar Prachi, P., 2010. Documentation of Wild edible plants of Melghat forest, Dist. Amaravati, Maharashtra state, India. Ethnobotanical Leaflet. 14, 751-58.

[6] Marathe, C.L., 2012. Sustainable utilization of plant resources from tribal areas of Thane district Maharashtra. Ph.D. thesis submitted to North Maharashtra University, Jalgaon.

[7] Tapan, S., Basundhara, P., Chaudhari, K., 2017. Evaluation of nutritional Potential of five unexplored wild edible plants consumed by the tribal people of Arunachal Pradesh state in India. Journal of food and Nutritional Research. 5, 1-5.

[8] Saikia. P., Deka, D.C., 2013. Mineral content of some wild green leafy vegetables of North -East India. Journal of chemical and pharmaceutical research. 5(3), 117-121.

[9] Ramachandran, V.S., 2007. Wild edible plants of the Anamalai Coimbatore district Western Ghats. Tamilnadu. Ind.J. Trad. Knowledge. 6(1), 173-176.

[10] Sundriyal, M., Sundriyal, R.C., Sharma, E., 2004. Dietary uses of wild plant resources in the Sikkim Himalayas. India. Econ.Bot. 58(4), 626-638.

[11] Majumdar, K., Datta, B.K., Ray, D., 2009. Traditional wild edible fruits for forest dwellers of Tripura. India. Pleione. 3(2), 172-180.

[12] Khyade, M.S., Kolhe, S.R., Deshmukh, B.S., 2009. Wild edible plants used by the tribes of Akola Tahsil of Ahmednagar District, (M.S.), India. Ethnobot. Leaflet. 13, 1328-36.

[13] Khan Tabassum, M.A., Kakde Umesh, B., 2014. Biodiversity in wild vegetables of Konkan region International Journal of Researches in Biosciences, Agriculture \& Technology. 2(1), 1-15.
[14] Satvi, V., Marathe, C.L., 2018. Wild Edible plants used as vegetable by rural communities of Palghar District, Maharashtra, India, Review of Research. 8(3), 1-5 .

[15] Almeda, M.R., 1996. Flora of Maharashtra. Volume-1-2.

[16] Cooke, T., 1967. The Flora of the Presidency of Bombay. Vol. I, II, III. Botanical Survey of India. Calcutta.

[17] Jain, S.K., Rao, R.R., 1977. A handbook of field and Herbarium methods. Today and Tomorrow's Printer Publisher, New Delhi.

[18] Shah, G.L., 1978. Flora of Gujarat state Saradar Patel University, V.V Nagar Gujarat.

[19] Naik, V.N., 1998. Marathwadyatil Samanya Vanaushhadhi (Marathi). Amrut Prakashan, Aurangabad.

[20] Nutrition news, 1996. National Institute of Nutrition, Hyderabad. 17, 2.

[21] Sundriyal, M., Sundriyal, R.C., Sharma, E., 2004. Dietary Use of Wild Plant Resources in the Sikkim Himalaya, India. Economic Botany. 58(4), 626-638.

[22] Bhogaonkar, P.Y., Marathe, V.R., Kshirsagar, P.P., 2010. Documentation of Wild Edible Plants of Melghat Forest, Dist. Amravati, Maharashtra State, India. Ethnobotanical Leaflets. 14, 751-758.

[23] Setiya, A.V., Narkhede, S.D., Dongarwar, N.M., 2016. Exploration and documentation of some wild edible plants used by the aboriginals from Gadchiroli District (M.S.) India. International Advanced Research Journal in Science, Engineering and Technology. 3(7), 24-35.

[24] Reddy, B.M., 2012. Wild edible plants of Chandrapur district, Maharashtra, India. Indian Journal of Natural Product and Resources. 3(1), 110-117.

[25] Rai, M., Singh, J., Pandey, A.K., 2004. Vegetables: A source of nutritional security. Indian Hort. 48(4), 1417.

[26] Kulkarni, D.K., 2006. Role of ethno-botany in Modern Agriculture. National Conference on Bridging Gap between Ancient and Modern Technologies to Increase Agricultural Productivity.

[27] Kulkarni, D.K., Agte, V.V., Kumbhojkar, M.S., 2003. Leafy vegetables consumed by Mahadeo Koli tribe in Western Maharashtra with their nutritional potential. Ethnobotany. 15, 34-38. 